\title{
Coffee consumption and risk of hepatocellular
}

\section{carcinoma: a meta-analysis of eleven epidemiological studies}

This article was published in the following Dove Press journal:

OncoTargets and Therapy

19 July 2016

Number of times this article has been viewed

\author{
Kai Bai* \\ Qiucheng Cai* \\ Yi Jiang \\ Lizhi Lv
}

Department of Hepatobiliary Surgery, Fuzong Clinical College, Fujian Medical University, Fuzhou, People's Republic of China

*These authors contributed equally to this work
Correspondence: Lizhi Lv Department of Hepatobiliary Surgery, Fuzong Clinical College, Fujian Medical University, 156 North Xi-er huan Road, Fuzhou 350025, People's Republic of China

Tel +86I58 60957758

Email Ivlizhi_fz@।63.com
Abstract: Growing evidence has shown that coffee consumption is inversely related with the risk of hepatocellular carcinoma. It is suggested that caffeine maintains strong antioxidative activity. With this property, coffee intake may lead to the inhibition of cell proliferation of liver cancer cells; also, some compounds contained in coffee can reduce the genotoxicity of aflatoxin B1 in vitro and lower the damage caused by some carcinogens. A computerized search was performed in PubMed to identify relevant articles published before August 2015. Eleven relevant studies were included with a total of 2,795 cases and 340,749 control subjects. According to the meta-analysis we performed, the pooled odds ratio (OR) from all included studies was 0.49 (95\% confidence interval $[\mathrm{CI}]=0.46-0.52)$. The subgroup analysis indicated that the pooled ORs for Asian studies and other populations were 0.27 (95\% CI $=0.23-0.31$ ) and $0.82(95 \% \mathrm{CI}=0.77-0.87)$, respectively. The overall pooled OR for high consumption was decreased to $0.21(95 \% \mathrm{CI}=0.18-0.25)$ and significance was observed. Among other populations, the pooled OR of subjects with high coffee consumption was 0.65 (95\% CI $=0.56-0.73$ ) compared to the nondrinker. The corresponding OR of five Asian studies was 0.13 (95\% $\mathrm{CI}=0.09-0.17$ ). The findings from this meta-analysis further confirmed the inverse association between the coffee consumption and hepatocellular carcinoma risk with quantitative evidence. The protective effect can be detected among healthy population and patients with chronic liver diseases, and the consumption can also prevent the development of liver cirrhosis.

Keywords: hepatocarcinogenesis, meta-analysis, coffee, antioxidant

\section{Introduction}

According to the statistics released by the World Health Organization, liver cancer currently occupies the fifth most common cancer in male and the seventh in female population. The incidence and mortality of liver cancer significantly vary with geographic region and sex. For instance, the incidence among male population in eastern Asia has reached 35.5 per 100,000 and the corresponding figure was only 12.6 among their counterparts. On the contrary, the more developed regions in worldwide range maintain a low incidence of liver cancer, and the incidence of males was down to 8.2 per 100,000 and 2.7 per 100,000 among females. ${ }^{1}$ Due to its high mortality, it is now qualified as the third common cause of death from cancer globally and also has become a major contributor of the world's burden of disease, especially in the less developed regions with vulnerable health care service.

It is generally acknowledged that chronic hepatitis B virus infection is the major risk factor for primary liver cancer and the prevalence of it can largely reflect the occurrence of cancer. ${ }^{2}$ To be more accurate, hepatitis $B$ virus infection may be responsible 
for $\sim 60 \%$ of liver cancer cases in less developed regions and for $\sim 23 \%$ in more developed regions. ${ }^{3}$ Hepatocellular carcinoma (HCC) accounts for $\sim 70 \%$ to $85 \%$ of all liver cancer diagnosed worldwide. ${ }^{4}$ Other factors, such as hepatitis $\mathrm{C}$ virus infection and aflatoxin $\mathrm{B} 1,{ }^{5}$ have also been related with the development of liver cancer in parts of Africa and Asia, and solid evidence has been acquired. ${ }^{6}$ Unlike the aforementioned regions, in some Western countries with low incidence, alcohol-related cirrhosis and possibly nonalcoholic fatty liver disease, associated with obesity, are considered to account for the majority of liver cancer. ${ }^{7}$ Despite the diversity of risk factors involved with the development of liver cancer, hepatitis B vaccination has now become the most effective and economic prevention against liver cancer. After the immunization program, remarkable, long-lasting protection against carriage and reduction of $\mathrm{HCC}$ rates in adolescent and young adults was observed in multiple study areas. ${ }^{8}$ Besides, the regular application of antiviral therapy is also capable of lowering the risk of disease among patients with chronic infection, and the protective effect has been observed among Japanese population. ${ }^{9}$ More importantly, growing evidence demonstrated that coffee consumption is inversely related with the risk of HCC. It is suggested that caffeine maintains a strong antioxidative activity. ${ }^{10} \mathrm{With}$ this property, coffee intake may lead to the inhibition of cell proliferation of liver cancer cells; ${ }^{11}$ also, some compounds contained in coffee can reduce the genotoxicity of aflatoxin B1 in vitro ${ }^{12}$ and lower the damage caused by some carcinogens, such as N-nitrosodimethylamine and 2-amino-1-methyl-6phenylimidazopyridine. ${ }^{13}$ Several epidemiological studies have been conducted in multiple regions previously; ${ }^{14,15}$ in order to elucidate further the protective effect that coffee consumption renders, we performed this meta-analysis with an exclusive focus on evidence from epidemiological studies of coffee intake and HCC risk.

\section{Materials and methods Search strategy}

We performed a literature search using the PubMed database from inception to August 2015 to acquire a comprehensive list of publications containing risk estimates describing the association between coffee consumption and HCC. The following search terms were used: 1) coffee consumption or coffee intake; 2) liver cancer or hepatocellular carcinoma; 3) casecontrol study; and 4) cohort study or prospective study. In order to detect all possible related publications, no language limitation was applied to the search. In addition, all references cited in these included publications were reviewed to identify additional published articles not shown in PubMed.

\section{Study selection}

Studies were included in our meta-analysis if they met the following criteria: 1) cohort studies or case-control studies; 2) the outcome is HCC; 3) the study factors include the consumption of coffee; 4) peer-reviewed articles with original data; 5) number of subjects, estimation of relative risk or odds ratio (OR), and their $95 \%$ confidence interval (CI) were demonstrated in detail; and 6) adjustment for confounding factors. During our search, we found that there were two studies published by the same author and with overlapping subjects. Therefore, we included the later publication with the updated data in our study..$^{16,17}$

Information was recorded into STATA version 12.0 (StataCorp LP, College Station, TX, USA) independently by two investigators according to the criteria. The following data were extracted: the first author's surname, year of publication, study design, coffee consumption, number of subjects, and control of confounding factors.

\section{Statistical analysis}

We calculated the pooled OR from all studies included with their corresponding $95 \% \mathrm{CI}$ to evaluate the association of coffee consumption with HCC risk. The significance of the pooled indicator was assessed by the $z$ test and a $P$-value of $<0.05$ was recognized as significant. Heterogeneity was determined by using $\chi^{2}$-based $Q$ test and $I^{2}$ statistic. ${ }^{18}$ When $P<0.10$ or $I^{2}>50 \%$, random effect model proposed by DerSimonian and Laird ${ }^{19}$ was employed to estimate the pooled OR. As for the absence of heterogeneity, a fixed-effect model was applied. The publication bias was evaluated by using Begg's asymmetry method with funnel plots and Egg's test.

In order to identify the protective effect among different ethnicities, we performed the subgroup analysis in accordance with the study populations. All enrolled studies were categorized into two types: Asian studies and other populations. As can be inferred from the previous studies, the variation of coffee consumption may also contribute to the difference on the protective effect it renders. To evaluate the effect of different levels of consumption more precisely, we further calculated the pooled OR for low or moderate consumption and high consumption. Concerning the different variable definition between studies, low or moderate consumption was defined as $<1$ cup per day for Kurozawa et al, ${ }^{20}$ Ohfuji et al, ${ }^{21}$ Tanaka et al, ${ }^{22}$ and 
Leung et al, ${ }^{23}$ and as $<3$ cups per day for Inoue et al, ${ }^{14}$ Kuper et al, ${ }^{16}$ Gallus et al, ${ }^{15}$ Gelatti et al, ${ }^{17}$ Montella et al, ${ }^{24}$ Johnson et al, ${ }^{25}$ and Setiawan et al. ${ }^{26}$ As for high consumption, it was defined as $>1$ cup per day for Kurozawa et al, ${ }^{20}$ Ohfuji et al, ${ }^{21}$ Tanaka et al, ${ }^{22}$ and $>3$ cups per day for Inoue et al, ${ }^{14}$ Kuper et al, ${ }^{16}$ Gallus et al, ${ }^{15}$ Gelatti et al, ${ }^{17}$ Montella et al, ${ }^{24}$ Johnson et al, ${ }^{25}$ and Setiawan et al. ${ }^{26}$ All statistical analyses were performed by STATA software version 12 . Unless otherwise specified, a $P$-value of $<0.05$ was considered statistically significant.

\section{Results}

\section{Studies included in the meta-analysis}

With the search strategy stated before, eleven relevant studies were included in our meta-analysis and data were extracted. Table 1 summarizes the characteristics of the eleven enrolled studies. There were three cohort studies and eight case-control studies. Six studies were conducted among Asian population and five among other subjects. In total, 2,795 cases and 340,749 control subjects were enrolled in our meta-analysis.

\section{Drinker versus nondrinker}

Initially we performed the meta-analysis to calculate the pooled OR by comparing the $\mathrm{HCC}$ risk of drinker and nondrinker. For the purpose of identifying the variation of protective effect among different population, we further estimated the risk indicator by ethnicity. As demonstrated in Figure 1, the pooled OR from all included studies was 0.49 (95\% CI $=0.46-0.52)$. The subgroup analysis indicated that the pooled ORs for other population and Asian studies were $0.82(95 \% \mathrm{CI}=0.77-0.87)$ and 0.27 (95\% CI $=0.23-0.31)$, respectively. Based on the result of $\mathrm{Q}$ test and $I^{2}$ statistic, heterogeneity was found within Asian studies and between subgroups; therefore, a random effect model was applied to calculate the aforementioned ORs.

\section{Low or moderate consumption versus nondrinker}

Figure 2 demonstrated the association between low or moderate consumption and risk of HCC. Heterogeneity has been detected within Asian studies and between subgroups, and therefore, we used a random effect model to estimate the pooled ORs. The meta-analysis suggested that low or moderate consumption was not able to reduce the HCC risk significantly among other populations with an OR of 0.95 (95\% CI $=0.86-1.05)$. However, the protective effect can be observed among overall population and Asian studies. According to the results obtained from Asian studies, the HCC risk among population with low or moderate consumption was reduced to $0.41(95 \% \mathrm{CI}=0.35-0.48)$ when compared with participants who have no coffee consumption. As for overall analysis for all studies, the ORs reached $0.57(95 \% \mathrm{CI}=0.52-0.62)$ with statistical significance.

\section{High consumption versus nondrinker}

As can be seen in Figure 3, the overall pooled OR for high consumption decreased to $0.21(95 \% \mathrm{CI}=0.18-0.25)$ and significance was observed. Among other populations, the pooled OR of subjects with high coffee consumption was 0.65 (95\% $\mathrm{CI}=0.56-0.73)$ compared to the nondrinker. The corresponding OR of five Asian studies was 0.13 (95\% CI $=0.09-0.17)$. It must be pointed out that the study conducted by Leung et $\mathrm{al}^{23}$ has no data on the high coffee consumption; therefore, this study has not been included in this section of metaanalysis. Due to the heterogeneity observed, random effect model was also employed in this estimation.

Table I Characteristics of studies included in the meta-analysis

\begin{tabular}{|c|c|c|c|c|c|c|}
\hline Authors & Year & Design & Ethnicity & Number of cases & Number of control/size of cohort & Duration of follow-up \\
\hline Kurozawa et al ${ }^{20}$ & 2005 & Cohort study & Asian & 258 & 83,996 & II years \\
\hline Ohfuji et $\mathrm{al}^{21}$ & 2006 & Case-control & Asian & 73 & 253 & - \\
\hline Tanaka et $\mathrm{al}^{22}$ & 2007 & Case-control & Asian & 209 & $\mathrm{I}, 253$ & - \\
\hline Leung et $\mathrm{a}^{23}$ & 2011 & Case-control & Asian & 109 & 125 & - \\
\hline Inoue et $\mathrm{al}^{14}$ & 2005 & Cohort study & Asian & 334 & 90,452 & 10 years \\
\hline Kuper et $\mathrm{al}^{16}$ & 2000 & Case-control & Other & 333 & 360 & - \\
\hline Gallus et $\mathrm{al}^{15}$ & 2002 & Case-control & Other & 501 & $\mathrm{I}, 552$ & - \\
\hline Gelatti et $\mathrm{al}^{17}$ & 2005 & Case-control & Other & 250 & 500 & - \\
\hline Montella et $\mathrm{al}^{24}$ & 2007 & Case-control & Other & 185 & 412 & - \\
\hline Johnson et $\mathrm{al}^{25}$ & 2011 & Case-control & Asian & 92 & 275 & - \\
\hline Setiawan et $\mathrm{al}^{26}$ & 2015 & Cohort study & Other & 451 & 162,022 & 18 years \\
\hline
\end{tabular}

Note: “-” no follow-up. 


\section{Study ID}

Other

Gallus et al ${ }^{15}$

Gelatti et al ${ }^{17}$

Kuper et $\mathrm{al}^{16}$

Montella et $\mathrm{al}^{24}$

Setiawan et $\mathrm{al}^{26}$

Subtotal $\left(I^{2}=60.6 \%, P=0.038\right)$

\section{Asian}

Inoue et al ${ }^{14}$

Johnson et $\mathrm{al}^{25}$

Kurozawa et $\mathrm{al}^{20}$

Leung et $\mathrm{al}^{23}$

Ohfuji et $\mathrm{al}^{21}$

Tanaka et $\mathrm{al}^{22}$

Subtotal $\left(I^{2}=93.8 \%, P=0.000\right)$

Heterogeneity between groups: $P=0.000$ Overall $\left(I^{2}=97.4 \%, P=0.000\right)$
ES $(95 \% \mathrm{Cl})$

Weight $(\%)$

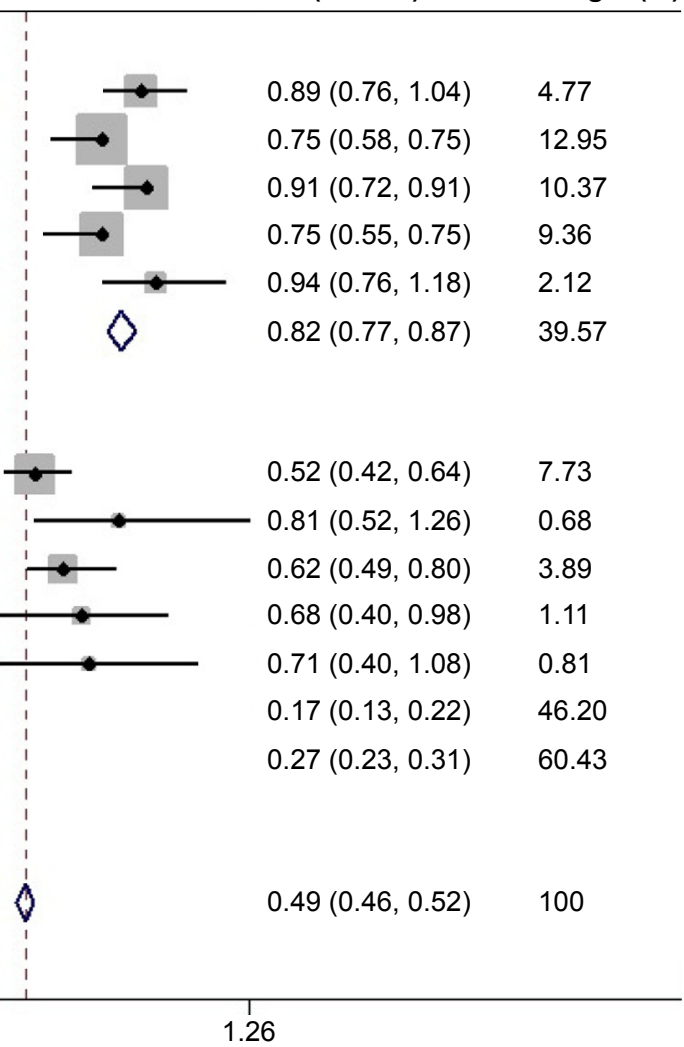

Figure I Overall and subgroup analyses for coffee drinkers versus nondrinkers with pooled ORs of developing HCC. Abbreviations: $\mathrm{Cl}$, confidence interval; $\mathrm{HCC}$, hepatocellular carcinoma; OR, odds ratio; $\mathrm{ES}$, effect size.

Study ID

\section{Other}

Gallus et $a^{15}$

Gelatti et al ${ }^{17}$

Kuper et al ${ }^{16}$

Montella et $\mathrm{al}^{24}$

Setiawan et $a^{26}$

Subtotal $\left(I^{2}=0.0 \%, P=0.803\right)$

\section{Asian}

Inoue et $\mathrm{al}^{14}$

Johnson et $\mathrm{al}^{25}$

Kurozawa et $\mathrm{al}^{20}$

Leung et al ${ }^{23}$

Ohfuji et al ${ }^{21}$

Tanaka et $\mathrm{al}^{22}$

Subtotal $\left(I^{2}=81.8 \%, P=0.000\right)$

Heterogeneity between groups: $P=0.000$ Overall $\left(I^{2}=91.3 \%, P=0.000\right)$
ES $(95 \% \mathrm{Cl})$

$1.02(0.87,1.19) \quad 10.48$

$0.86(0.66,1.12) \quad 5.07$

$0.94(0.74,1.20) \quad 5.07$

$0.87(0.63,1.21) \quad 3.19$

$0.96(0.77,1.21) \quad 5.54$

$0.95(0.86,1.05) \quad 29.34$

く $\quad 0.95(0.86,1.05) \quad 29.34$

$0.41(0.32,0.52) \quad 26.82$

$0.85(0.55,1.33) \quad 1.76$

$0.89(0.64,1.23) \quad 3.08$

$0.68(0.47,0.98) \quad 4.12$

$0.72(0.43,1.21) \quad 1.76$

$0.30(0.22,0.40) \quad 33.11$

$0.41(0.35,0.48) \quad 70.66$

$0.57(0.52,0.62) \quad 100$

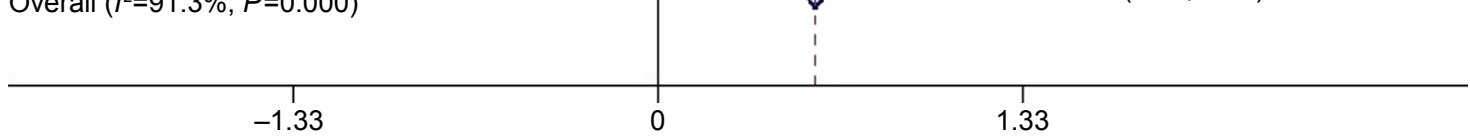

Figure 2 Overall and subgroup analyses for low or moderate consumption versus nondrinkers with pooled ORs of developing HCC.

Abbreviations: $\mathrm{Cl}$, confidence interval; $\mathrm{HCC}$, hepatocellular carcinoma; OR, odds ratio; $\mathrm{ES}$, effect size. 


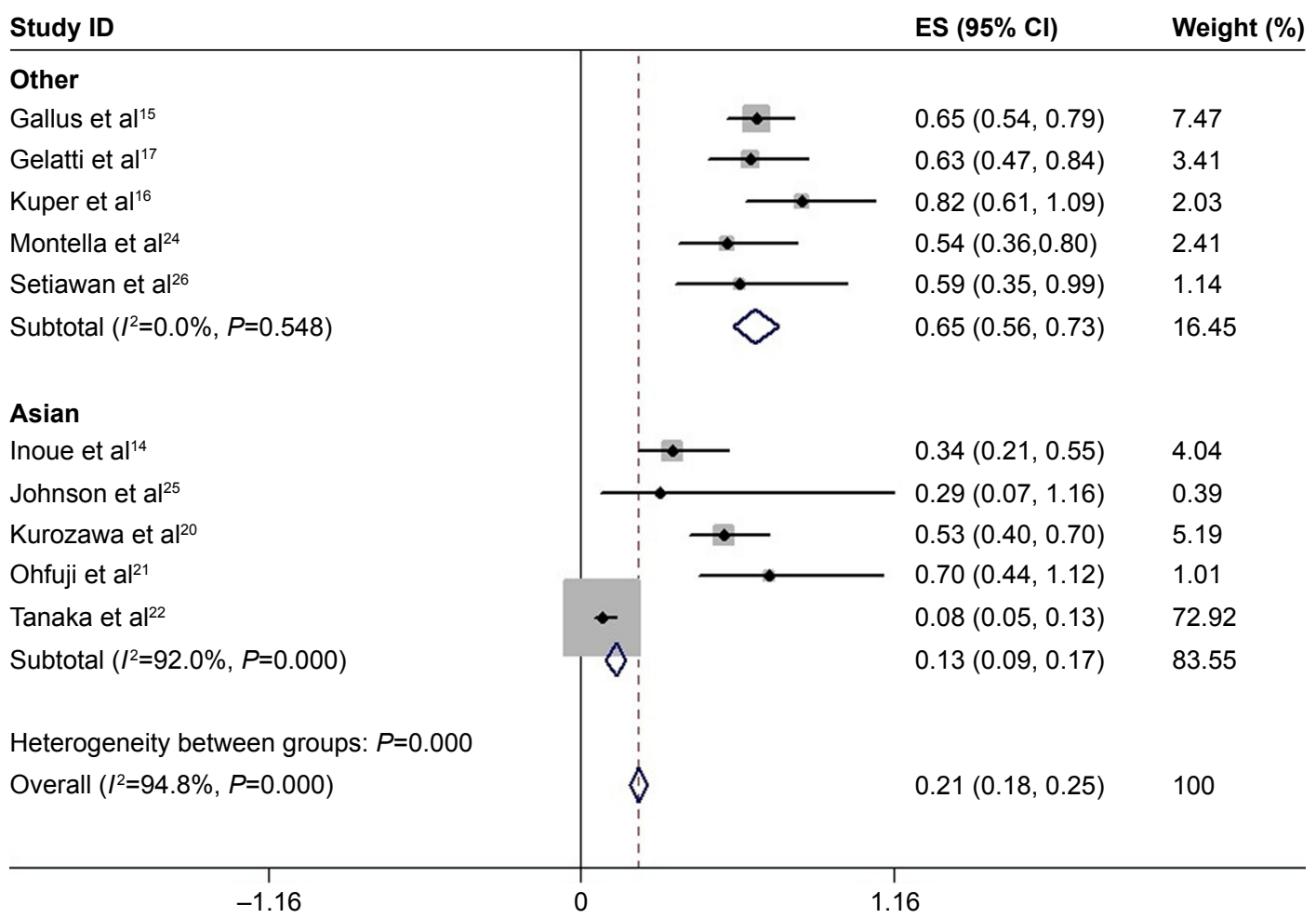

Figure 3 Overall and subgroup analyses for high consumption versus nondrinkers with pooled ORs of developing HCC. Abbreviations: $\mathrm{Cl}$, confidence interval; $\mathrm{HCC}$, hepatocellular carcinoma; OR, odds ratio; ES, effect size.

\section{Publication bias}

We used funnel plot to evaluate the publication bias in this meta-analysis. And the shape of funnel plot suggested an approximate symmetry result. In addition, the $P$-values calculated by Egger's test were $>0.05$, serving as the statistical evidence for the funnel plot. Therefore, we can assume that the publication bias was not obvious in our meta-analysis.

\section{Discussion}

Some previously conducted studies in Europe and Asia investigating the association of coffee consumption with risk of HCC reported inconsistent results. We performed the metaanalysis with the latest resource to update and improve the available evidence on the association in the introduction section. As can be seen in Table 2, the pooled OR for drinkers in all studies was $0.49(95 \% \mathrm{CI}=0.46-0.52)$ compared with those with no coffee intake. Subgroup analysis by the level of consumption also suggested an inverse and significant association between coffee intake and HCC risk, except for low or moderate consumption among other populations (pooled OR $=0.95,95 \% \mathrm{CI}=0.86-1.05$ ).

The inverse association established by meta-analysis might be confounded with the health status of participants. As in daily life, patients with a broad spectrum of digestive tract diseases, liver disorders, and cirrhosis are more likely to avoid coffee consumption. However, the prospective study conducted by Inoue et a $\mathrm{a}^{14}$ demonstrated that coffee consumption can significantly reduce the HCC risk among hepatitis $\mathrm{C}$ virus-positive patients with a hazards ratio of 0.57 (95\% $\mathrm{CI}=0.37-0.86$ ). In addition, Tanaka et $\mathrm{al}^{22}$ recruited patients with chronic liver disease as control, and reduced risk has also been observed among the subjects with coffee consumption. Given the solid statistical power and credibility provided by

Table 2 Pooled ORs and its $95 \% \mathrm{Cl}$ for coffee consumption and $\mathrm{HCC}$ risk

\begin{tabular}{lcl}
\hline & $\begin{array}{l}\text { Pooled } \\
\text { OR }(95 \% \mathrm{CI})\end{array}$ & Model applied \\
\hline Drinker versus nondrinker & & \\
Other populations & $0.82(0.77-0.87)^{*}$ \\
Asian populations & $0.27(0.23-0.31)^{*}$ \\
Overall & $0.49(0.46-0.52)^{*}$ & Random effect \\
Low or moderate consumption versus nondrinker \\
Other populations & $0.95(0.86-1.05)$ \\
Asian populations & $0.4 I(0.35-0.48)^{*}$ \\
Overall & $0.57(0.52-0.62)^{*}$ & Random effect \\
High consumption versus nondrinker & \\
Other populations & $0.65(0.56-0.73)^{*}$ \\
Asian populations & $0.13(0.09-0.17)^{*}$ \\
Overall & $0.21(0.18-0.25)^{*}$ Random effect \\
\hline
\end{tabular}

Note: $* P<0.05$.

Abbreviations: $\mathrm{Cl}$, confidence interval; $\mathrm{HCC}$, hepatocellular carcinoma; OR, odds ratio. 
the cohort study and evidence acquired from other resources, we can basically rule out this potential bias.

Coffee consumption may decrease the risk of HCC in several possible ways. For instance, cell experiments indicated that caffeine may inhibit the proliferation of liver cancer cells via cell cycle arrest, which is independent of apoptosis, and, moreover, mitogen-activated protein kinase/ extracellular signal regulated kinase/epidermal growth factor receptor signaling pathway is activated by a major component of coffee. ${ }^{11}$ An animal experiment conducted by Lv et $\mathrm{al}^{27}$ suggested that caffeine is capable of protecting liver injury; to be more specific, it can reduce the hepatic cell damage and inflammation. Evidence from a random trial performed in Wistar rats demonstrated the consumption of caffeine can significantly reduce the serum levels of alanine aminotransferase and oxidized glutathione and transforming growth factor beta 1 protein expression and other liver injury indicators. ${ }^{28}$ Birerdinc et $\mathrm{al}^{29}$ also observed that caffeine intake was inversely associated with the risk of nonalcoholic fatty liver disease among American population. It is reported that unfiltered coffee contains substantial quantities of kahweol and cafestol. Apart from their detoxification against aflatoxin $\mathrm{B} 1^{12}$ and N-nitrosodimethylamine, ${ }^{13}$ the substances are also capable of suppressing the viability of MSTO-211H and $\mathrm{H} 28$ cells and apoptotic cell death was observed in MSTO-211H cell. The activation of Bid, Caspase-3, and poly ADP-ribose polymerase with cafestol and upregulation were validated via immunoblotting technique. ${ }^{30}$ Therefore, the anticarcinogenic effect of coffee has been confirmed with multiple biological assays. It is currently acknowledged that liver cirrhosis is strongly associated with the risk of developing HCC. An animal experiment conducted by Moreno et $\mathrm{al}^{31}$ reported that coffee administration among rats can improve the liver function and prevent the carbon tetrachloride-induced liver cirrhosis. Epidemiological evidence on the protective effect against cirrhosis has also been acquired from a cohort study conducted in Norway; ${ }^{32}$ with the follow-up of 51,306 participants, the relative risk for the consumption of coffee (two cups or more per day) was 0.6 (95\% CI $=0.5-0.8)$, and the effect was also confirmed among the subjects with alcoholic cirrhosis. The aforementioned effects were also observed among Italian ${ }^{33}$ and American populations. ${ }^{34}$

Coffee consumption may also reduce the risk of $\mathrm{HCC}$ in a more indirect way. Chlorogenic acids which can be found in coffee maintain the capacity of lowering fasting blood glucose in diabetic $(\mathrm{db} / \mathrm{db})$ mice; in addition, the author also reported the stimulation of glucose transport caused by the acids in vitro. ${ }^{35}$ A study with 2,332 subjects has been conducted among Chinese population in Taiwan, ${ }^{36}$ and the inverse association between high coffee intake and diabetes risk has been observed with a crude OR of $0.29(95 \%$ $\mathrm{CI}=0.14-0.64)$. Multiple studies have suggested that diabetes might be an independent risk factor for HCC, and epidemiological evidence has been acquired among Japanese ${ }^{37}$ and Italian population. ${ }^{38,39}$ Moreover, a latest meta-analysis ${ }^{40}$ that included 32 cohort studies and 17 case-control studies has estimated the relative risk for the HCC risk among diabetic subjects, and the figure reached 2.31 (95\% CI $=1.87-2.84)$. Due to the beneficial effect against diabetes that coffee can offer, we may infer that the reduced risk of HCC rendered by coffee intake could possibly be mediated through the decreased risk of diabetes.

In summary, the findings from this meta-analysis further confirmed the inverse association between the coffee consumption and HCC risk with quantitative evidence. The protective effect can be detected among healthy population and patients with chronic liver diseases, and the consumption can also prevent the development of liver cirrhosis. Thus, the promotion of coffee consumption should be performed to reduce the risk of HCC. However, both biological research and epidemiological study should be further conducted to illustrate and validate the protective effect it renders.

\section{Acknowledgment}

This study has been financially supported by Key program (No 2014Y0034) of Fujian Provincial Department of Science and Technology.

\section{Disclosure}

The authors report no conflicts of interest in this work.

\section{References}

1. Torre LA, Bray F, Siegel RL, Ferlay J, Lortet-Tieulent J, Jemal A. Global cancer statistics. CA Cancer J Clin. 2015;65(2):87-108.

2. Schottenfeld D, Fraumeni FJ Jr. Liver Cancer. Cancer Epidemiology and Prevention. 3rd ed. New York: Oxford University Press; 2006.

3. Parkin DM. The global health burden of infection-associated cancers in the year 2002. Int J Cancer. 2006;118(12):3030-3044.

4. Perz JF, Armstrong GL, Farrington LA, Hutin YJ, Bell BP. The contributions of hepatitis $\mathrm{B}$ virus and hepatitis $\mathrm{C}$ virus infections to cirrhosis and primary liver cancer worldwide. $J$ Hepatol. 2006;45(4): 529-538.

5. Villar S, Ortiz-Cuaran S, Abedi-Ardekani B, et al. Aflatoxin-induced TP53 R249S mutation in hepatocellular carcinoma in Thailand: association with tumors developing in the absence of liver cirrhosis. PLoS One. Epub 2012 Jun 4.

6. Kumar V, Kato N, Urabe Y, et al. Genome-wide association study identifies a susceptibility locus for HCV-induced hepatocellular carcinoma. Nat Genet. 2011;43(5):455-458.

7. El-Serage HB. Epidemiology of hepatocellular carcinoma in USA. Hepatol Res. 2007;37(Suppl 2):S88-S94. 
8. Plymoth A, Viviani S, Hainaut P. Control of hepatocellular carcinoma through hepatitis B vaccination in areas of high endemicity: perspectives for global liver cancer prevention. Cancer Lett. 2009;286(1):15-21.

9. Kurokawa M, Hiramatsu N, Oze T, et al. Long-term effect of lamivudine treatment on the incidence of hepatocellular carcinoma in patients with hepatitis B virus infection. J Gastroenterol. 2012;47(5):577-585.

10. Azam S, Hadi N, Khan NU, Hadi SM. Antioxidant and prooxidant properties of caffeine, theobromine and xanthine. Med Sci Monit. 2003; 9(9):BR325-BR330.

11. Okano J, Nagahara T, Matsumoto K, Murawaki Y. Caffeine inhibits the proliferation of liver cancer cells and activates the MEK/ERK EGFR signaling pathway. Basic Clin Pharmacol Toxicol. 2008;102(6): 543-551.

12. Cavin C, Mace K, Offord EA, Schilter B. Protective effects of coffee diterpenes against aflatoxin B1-induced genotoxicity: mechanisms in rat and human cells. Food Chem Toxicol. 2001;39(6):549-556.

13. Cavin C, Holzhaeuser D, Scharf G, Schilter B. Cafestol and kahweol, two coffee specific diterpenes with anticarcinogenic activity. Food Chem Toxicol. 2002;40(8):1155-1163.

14. Inoue M, Yoshimi I, Sobue T, Tsugane S. Influence of coffee drinking on subsequent risk of hepatocellular carcinoma: a prospective study in Japan. J Natl Cancer Inst. 2005;97(4):293-300.

15. Gallus S, Bertuzzi M, Tavani A, et al. Does coffee protect against hepatocellular carcinoma. Br J Cancer. 2002;87(8):956-959.

16. Kuper H, Tznou A, Kaklamani E, et al. Tobacco smoking, alcohol consumption and their interaction in the causation of hepatocellular carcinoma. Int J Cancer. 2000;85(4):498-502.

17. Gelatti U, Covolo L, Franceschini M, et al. Coffee consumption reduces the risk of hepatocellular carcinoma independently of its aetiology: a case-control study. J Hepatol. 2005;42(4):528-534.

18. Higgins JP, Thompson SG, Deeks JJ, Altman DG. Measuring inconsistency in meta-analyses. BMJ. 2003;327(7414):557-560.

19. DerSimonian R, Laird N. Meta-analysis in clinical trials. Control Clin Trials. 1986;7(3):177-188.

20. Kurozawa Y, Ogimoto I, Shibata A, et al. Coffee and risk of death from hepatocellular carcinoma in a large cohort study in Japan. Br J Cancer. 2005;93(5):607-610.

21. Ohfuji S, Fukushima W, Tanaka T, et al. Coffee consumption and reduced risk of hepatocellular carcinoma among patients with chronic type C liver disease: a case-control study. Hepatol Res. 2006;36(3): 201-208.

22. Tanaka K, Hara M, Sakamoto T, et al. Inverse association between coffee drinking and the risk of hepatocellular carcinoma: a case-control study in Japan. Cancer Sci. 2007;98(2):214-218.

23. Leung WW, Ho SC, Chan HL, Wong V, Yeo W, Mok TS. Moderate coffee consumption reduces the risk of hepatocellular carcinoma in hepatitis B chronic carriers: a case-control study. J Epidemiol Community Health. 2011;65(6):556-558.

24. Montella M, Polesel J, La Vecchia C, et al. Coffee and tea consumption and risk of hepatocellular carcinoma in Italy. Int J Cancer. 2007;120(7): 1555-1559.
25. Johnson S, Koh WP, Wang R, Govindarajan S, Yu MC, Yuan JM. Coffee consumption and reduced risk of hepatocellular carcinoma: findings from the Singapore Chinese Health Study. Cancer Cause Control. 2011; 22(3):503-510.

26. Setiawan VW, Wilkens LR, Lu SC, Hernandez BY, Le Marchand L, Henderson BE. Association of coffee intake with reduced incidence of liver cancer and death from chronic liver disease in the US multiethnic cohort. Gastroenterology. 2015;148(1):118-125.

27. Lv X, Chen Z, Li J, et al. Caffeine protects against alcoholic liver injury by attenuating inflammatory response and oxidative stress. Inflamm Res. 2010;59(8):635-645.

28. Furtado KS, Prado MG, Aguiar E, Silva MA, et al. Coffee and Caffeine protects against liver injury induced by thioacetamide in male wistar rats. Basic Clin Pharmacol Toxicol. 2012;111(5):339-347.

29. Birerdinc A, Stepanova M, Pawloski L, Younossi ZM. Caffeine is protective in patients with non-alcoholic fatty liver disease. Aliment Pharmacol Ther. 2012;35(1):76-82.

30. Lee KA, Chae JI, Shim JH. Natural diterpenes from coffee, cafestol and kahweol induce apoptosis through regulation of specificity protein 1 expression in human malignant pleural mesothelioma. J Biomed Sci. 2012;19:60

31. Moreno MG, Chavez E, Aldaba-Muruato LR, et al. Coffee prevents CCI(4)induced liver cirrhosis in the rat. Hepatol Int. 2011;5(3):857-863.

32. Tverdal A, Skutveit S. Coffee intake and mortality from liver cirrhosis. Ann Epidemiol. 2003;13(6):419-423.

33. Corrao G, Zambon A, Baqnardi V, D’Amicis A, Klatsky A. Coffee, caffeine, and the risk of liver cirrhosis. Ann Epidemiol. 2001;11(7): $458-465$.

34. Klatsky AL, Armstrong MA. Alcohol, smoking, coffee, and cirrhosis. Am J Epidemiol. 1992;136(10):1248-1257.

35. Ong KW, Hsu A, Tan BK. Chlorogenic acid stimulates glucose transport in skeletal muscle via AMPK activation: a contributor to the beneficial effects of coffee on diabetes. PLoS One. Epub 2012 Mar 7.

36. Lin WY, Xaiver Pi-Sunyer F, Chen CC, et al. Coffee consumption is inversely associated with type 2 diabetes in Chinese. Eur J Clin Invest. 2011;41(6):659-666.

37. Matsuo M. Association between diabetes mellitus and hepatocellular carcinoma: results of a hospital and community-based case-control study. Kurume Med J. 2003;50(3-4):91-98

38. Polesel J, Zucchetto A, Montella M, et al. The impact of obesity and diabetes mellitus on the risk of hepatocellular carcinoma. Ann Oncol. 2009;20(2):353-357.

39. Donadon V, Balbi M, Casarin P, Vario A, Alberti A. Association between hepatocellular carcinoma and type 2 diabetes mellitus in Italy: potential role of insulin. World J Gastroenterol. 2008;14(357):5695-5700.

40. Wang P, Kang D, Cao W, Wang Y, Liu Z. Diabetes mellitus and risk of hepatocellular carcinoma: a systematic review and meta-analysis. Diabetes Metab Res Rev. 2012;28(2):109-122.
OncoTargets and Therapy

\section{Publish your work in this journal}

OncoTargets and Therapy is an international, peer-reviewed, open access journal focusing on the pathological basis of all cancers, potential targets for therapy and treatment protocols employed to improve the management of cancer patients. The journal also focuses on the impact of management programs and new therapeutic agents and protocols on

\section{Dovepress}

patient perspectives such as quality of life, adherence and satisfaction. The manuscript management system is completely online and includes a very quick and fair peer-review system, which is all easy to use. Visit http://www.dovepress.com/testimonials.php to read real quotes from published authors. 